This is the author's final, peer-reviewed manuscript as accepted for publication. The publisher-formatted version may be available through the publisher's web site or your institution's library.

\title{
Serine and cysteine protease-like genes in the genome of a gall midge and their interactions with host plant genotypes
}

Hang Chen, Yu Cheng Zhu, R. Jeff Whitworth, John C. Reese, and Ming-Shun Chen

\section{How to cite this manuscript}

If you make reference to this version of the manuscript, use the following information:

Chen, H., Zhu, Y. C., Whitworth, R. J., Reese, J. C., \& Chen, M.-S. (2013). Serine and cysteine protease-like genes in the genome of a gall midge and their interactions with host plant genotypes. Retrieved from http://krex.ksu.edu

\section{Published Version Information}

Citation: Chen, H., Zhu, Y. C., Whitworth, R. J., Reese, J. C., \& Chen, M.-S. (2013). Serine and cysteine protease-like genes in the genome of a gall midge and their interactions with host plant genotypes. Insect Biochemistry and Molecular Biology, 43(8), 701-711.

Copyright: Published by Elsevier Ltd.

Digital Object Identifier (DOI): doi:10.1016/j.ibmb.2013.05.006

Publisher's Link: http://www.sciencedirect.com/science/article/pii/S0965174813001008

This item was retrieved from the K-State Research Exchange (K-REx), the institutional repository of Kansas State University. K-REx is available at http://krex.ksu.edu 
21

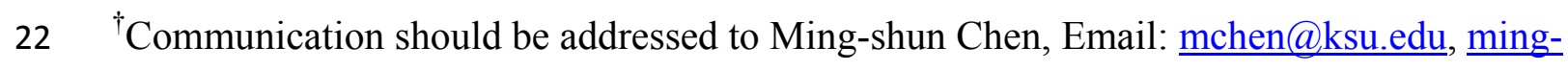
23 shun.chen@ars.usda.gov. Phone: 785-532-4719. Fax: 785-532-6232.

\section{Serine and Cysteine Protease-like Genes in the Genome of a Gall} Midge and Their Interactions with Host Plant Genotypes*

Hang Chen ${ }^{1,2}$, Yu Cheng Zhu ${ }^{3}$, R. Jeff Whitworth ${ }^{1}$, John C. Reese ${ }^{1}$, and Ming-Shun Chen ${ }^{1,4 \dagger}$

${ }^{1}$ Department of Entomology, Kansas State University, Manhattan, KS 66506, USA

${ }^{2}$ Research Institute of Resource Insect, Chinese Academy of Forestry, Kunming 650224, China ${ }^{3}$ USDA-ARS-JWDSRC, PO Box 346/141 Exp Stn Rd, Stoneville, MS 38776, USA

${ }^{4}$ Hard Winter Wheat Genetics Research Unit, USDA-ARS, 4008 Throckmorton Hall, Kansas State University, Manhattan, KS 66506

*Mention of trade names or commercial products in this publication is solely for the purpose of providing specific information and does not imply recommendation or endorsement by the U.S. Department of Agriculture. USDA is an equal opportunity provider and employer.

Keywords: Hessian fly genome, Mayetiola destructor, serine protease, cysteine protease, gut proteinases. 


\section{Abstract}

Proteases play important roles in a wide range of physiological processes in organisms.

26 For plant-feeding insects, digestive proteases are targets for engineering protease inhibitors for

27 pest control. In this study, we identified 105 putative serine- and cysteine-protease genes from

28 the genome of the gall midge Mayetiola destructor (commonly known as Hessian fly), a

29 destructive pest of wheat. Among the genes, 31 encode putative trypsins, 18 encode putative

30 chymotrypsins, seven encode putative cysteine proteases, and the remaining may encode either other proteases or protease homologues. Developmental stage- and tissue-specific expression

32 profiles of the genes encoding putative trypsins, chymotrypsins, and cysteine proteases were

33 determined by quantitative reverse-transcription PCR. Comparative analyses of stage- and

34 tissue-specific expression patterns suggested that several genes are likely to encode digestive

35 proteases in the $M$. destructor larval gut, including genes encoding putative trypsins MDP3, MDP5, MDP9, MDP24, MDP48, MDP51, MDP57, MDP61, MDP71, and MDP90; genes

37 encoding putative chymotrypsins MDP1, MDP7, MDP8, MDP18, MDP19, and MDP20; and

38 genes encoding putative cysteine proteases MDP95 and MDP104. The expression of some protease genes was affected by plant genotypes. Genes encoding trypsins MDP3, MDP9, and MPD23, chymotrypsins MDP20 and MDP21, and cysteine proteases MDP99 and MDP104 were upregulated in $M$. destructor larvae feeding in resistant plants, whereas genes encoding trypsins

42 MDP12, MDP24, and MDP33, and chymotrypsins MDP8, MDP15, and MDP16 were

43 downregualted in $M$. destructor larvae feeding in resistant plants. This study provides a

44 foundation for further comparative studies on proteases in different insects, and further

45 characterization of $M$. destructor digestive proteases and their interactions with host plants, as 46 well as potential targets for transgenic wheat plants. 
Proteases are involved in various physiological and biochemical processes such as signal transduction, digestion, development, and defense reactions (Neurath and Walsh, 1976; Barrett et

50 al., 1998; Neurath, 1999). In plant-feeding insects, proteases are involved in plant - insect

51 interactions and participate in the arms race between hosts and herbivores (Bown et al., 1997;

52 Pechan et al., 2002; Jongsma and Beekwilder, 2011). In herbivorous insects, proteases produced 53 in salivary glands can be injected into host plants for pre-oral digestion and for removing toxic 54 proteins produced by plants for defense (Miles, 1999; Eberhard et al., 2007). In the gut of most 55 insects, the main role of proteases is to digest proteins ingested from host plants (Shukle et al., 56 1985; Lopes et al., 2006; Wright et al., 2006; Sato et al., 2008). During the long course of co57 evolution, plants have developed defense mechanisms that suppress protease activities in the 58 insect digestive system. Specifically, plants enhance the production of various protease 59 inhibitors that reduce activities of insect digestive proteases in response to herbivory (Moura and 60 Ryan, 2001; Habib and Fazili, 2007; Chen, 2008). Accordingly, these plant inhibitors could be 61 targets for genetic engineering to increase plant resistance to herbivorous pests (Burgess et al., 62 1994; Murdock et al., 1988; Lawrence and Koundal, 2002). However, insects have also 63 developed counter-defense mechanisms including up-regulation of constitutively expressed 64 digestive proteases, induction of proteases that are normally not expressed, and/or by 65 synthesizing inhibitor-insensitive proteases in response to plant defense (Jongsma et al., 1995; 66 Bown et al., 1997; Mazumdar-Leighton and Broadway, 2001; Ahn et al., 2004; Brioschi et al., 67 2007). In order to make plant protease inhibitors an effective tool for pest management, a 68 comprehensive understanding of protease composition in insect genomes and their regulatory 
mechanisms for expression in response to plant defense is needed to design feasible strategies for engineering plant inhibitors.

One of the gall midges, Mayetiola destructor, commonly known as the Hessian fly, is one of the most destructive arthropod pests of wheat (Hatchett et al., 1987; Buntin, 1999; Pauly 2002). The digestive proteases in Hessian fly larvae are apparently targets for plant defense under natural conditions because a range of protease inhibitors are highly upregulated in resistant wheat seedlings during incompatible interactions (Liu et al., 2007; Wu et al., 2008). The upregulated protease inhibitors in resistant wheat plants may be part of the defense mechanism that results in the death of Hessian fly larvae (Stuart et al., 2012). Transcriptomic analyses have identified several genes encoding trypsins and chymotrypsins that are exclusively or highly expressed in the gut of Hessian fly larvae (Zhu et al., 2005). Protease activity has also been detected in gut extract from Hessian fly larvae (Shukle et al., 1985). These observations indicate that digestive proteases in Hessian fly larval gut could be targets for engineering effective plant inhibitors to increase wheat resistance to the pest. A better understanding of the composition of proteases in the Hessian fly genome, major digestive proteases in different larval instars, and the expression dynamics of the protease genes in response to plant defense should provide useful information for utilizing protease inhibitors to enhance host resistance for controlling Hessian fly damage. The objectives of this research were to: 1) Identify putative serine- and cysteineprotease genes in the Hessian fly genome; 2) Identify digestive proteases in Hessian fly larval gut; 3) To determine expression patterns of major digestive protease genes at different larval stages; and 4) Determine changes in expression of protease genes in response to plant defense.

\section{Materials and methods}

\subsection{Hessian fly}


Hessian fly larvae used in this research were derived from a field collection from Scott

93 County, Kansas in 2005 (Chen et al., 2009). The insects have been maintained on seedlings of Hessian fly-susceptible wheat variety 'Karl 92' in greenhouse since then. The majority of flies were biotype GP although biotypes virulent to known R genes were also found in low frequencies (Chen et al., 2009).

\subsection{Identification of putative protease genes from the Hessian fly genome}

The overall conservation of different trypsins, chymtrypsins, and cysteine proteases in an organism and across different species facilitated the identification of new proteases within a genome. To identify potential new Hessian fly protease genes, the draft Hessian fly genome sequence ( http://agripestbase.org/hessianfly/) was searched using Blastx with known Hessian fly trypsins and chymotrypsins (Zhu et al., 2005), two partial sequences of Hessian fly cysteine proteases obtained from a gut transcriptome, and Drosophila serine- and cysteine-protease as queries (Matsumoto et al., 1995; Ross et al., 2003). From the resulting list of similar sequences, every 15 th sequence was retrieved for another round of blasting. All the amino acid sequences encoded by predicted genes with significant sequence similarity $(E$-value $<0.01)$ from each of queries were retrieved. Repeated blasting was carried out until no new hit with $E$-value $<0.01$ could be found. Introns were identified by comparing genomic sequence with a corresponding cDNA sequence or a putative transcript predicted by MAKER2 (Holt and Yandell, 2011). If no cDNA sequence or transcript was available for a particular gene, the intron/exon boundary was determined manually by a Blastx alignment between the Hessian fly gene sequence and the query protein sequence. Sequences were discarded if they could not be annotated. The identity of the annotatable sequences was further confirmed using MotifScan (Yusim et al., 2004) and 
114 ScanProsite tool (Gattiker et al., 2002) to reveal their characteristic sequence patterns and 115 putative enzyme active sites.

116

117

118

119

120

121

122

123

124

125

126

127

128

129

130

131

132 for normalization. DNA bands were photographed with a Bio Doc-It ${ }^{\mathrm{TM}}$ System (UVP, Upland,

133 CA) and band intensity was determined using Photoshop CS image analysis software (Adobe 134 Systems Incorporated, San Jose, California).

\subsection{RNA isolation and PCR analyses}

Total RNA was extracted from either whole flies or specific fly tissues using RNeasy

Micro Kit according to the procedure provided by the manufacturer (QIAGEN, Maryland, USA).

Whole body samples were extracted from larvae of 1, 3, 6, and 12 days old, respectively, pupae and adults. Tissue-specific samples were extracted from dissected guts, fat bodies, salivary glands, Malpighian tubules, and the remaining carcass. These tissues were obtained from 3-dayold larvae (first instar).

Primers were designed using the Beacon Designer 7.0 software (Biosoft, Palo Alto, CA). Primer sequences were listed in Table S1. RNA samples were treated with RNase-free DNase-I (Promega, Madison, WI) to remove potential DNA contamination. The RNA was then reversetranscribed into cDNA using (oligo-dT) ${ }_{20}$ primers with the SuperScript ${ }^{\circledR}$ III First-Strand Synthesis System (Invitrogen, Carlsbad, CA, USA).

For semi-quantitative PCR, amplification was carried out for 25 to 40 cycles, depending on the intensity of PCR products, as follows: $60 \mathrm{~s}$ at $94^{\circ} \mathrm{C} ; 60 \mathrm{~s}$ at $55^{\circ} \mathrm{C} ; 120 \mathrm{~s}$ at $72^{\circ} \mathrm{C}$. DNA fragments from the PCR reactions were separated on 1.5 to $2 \%$ agarose gels depending on the size of the product and stained with $(0.5 \mu \mathrm{g} / \mathrm{mL})$ ethidium bromide. Actin was used as a control

For quantitative real-time PCR (qPCR), amplification was performed with iQ SYBR Green Supermix on a iCycler real time detection system (Bio-Rad, Hercules, CA). Each reaction was carried out with $2 \mu \mathrm{l}$ of a $1 / 40(\mathrm{v} / \mathrm{v})$ dilution of the first cDNA strand, $0.5 \mu \mathrm{M}$ of each primer 
138 in a total volume of $25 \mu \mathrm{l}$. The cycling conditions were: $95^{\circ} \mathrm{C}$ for $5 \mathrm{~min}$ followed by 45 cycles of 139 denaturation at $95^{\circ} \mathrm{C}$ for $20 \mathrm{~s}$, annealing and extension at $62^{\circ} \mathrm{C}$ to $64.5^{\circ} \mathrm{C}$, depending on the 140 primer set, for $45 \mathrm{~s}$. At the end of the cycles, PCR amplification specificity was verified by 141 obtaining a dissociation curve, derived by cooling the denatured samples to $55^{\circ} \mathrm{C}$ and raising the 142 temperature $0.5^{\circ} \mathrm{C}$ for $10 \mathrm{~s}$ for each cycle, for a total of 80 cycles until reaching $95^{\circ} \mathrm{C}$. The PCR 143 products were analyzed on $1.5 \%$ agarose gels, and subsequently purified and sequenced to 144 confirm faithful amplification. Actin was selected as a reference for normalization of template 145 concentration. Three independent biological replicates were carried out for each treatment. by ANOVA using the PROCMIXED procedure of SAS (SAS institute Inc., SAS/STAT User's Guide, Version 9.13). Tukey's pairwise comparisons based on Student's range statistics were then conducted. Tukey's 95\% simultaneous confidence intervals for pair-wise comparisons were used to separate data into groups with significant differences.

\subsection{Sequence data processing and phylogenetic analysis}

Molecular weight calculations and pI prediction of mature proteins were carried out with

153 the 'Compute pI/Mw tool' (http://us.expasy.org/tools/pi tool.html, Bjellqvist et al., 1993).

154 Signal peptide cleavage sites were predicted using SignalP 4.1 Server (Petersen et al., 2011).

155 Multiple alignments of gene data matrices and protein sequences were generated using similarity 156 calculated with ClustalW (Larkin et al., 2007) and BioEdit (Ver. 5.09; Hall, 1999). Molecular 157 and phylogenetic analyses were conducted using MEGA Version 5 software (Tamura et al., 158 2011). The phylogeny was inferred by using the Maximum Likelihood (ML) method for 159 pairwise distance calculation. Phylogenetic tree was constructed using Neighbor Joining 160 (NJ) and BIONJ algorithms (Tamura et al., 2004). Bootstrap analyses were conducted (1000 
161 repeats) by the majority rule $(70 \%$ or above) for grouping to ensure nodal reliability (Felsenstein, 162 1985).

\section{Results}

\subsection{Serine and cysteine protease-like genes in the Hessian fly genome}

Blast searches of the Hessian fly genome with known Hessian fly and Drosophila

167 proteases (see Materials and Methods) identified 105 serine- and cysteine- protease genes. These 168 169 genes were named Mayetiola destructor protease 1 (MDP1) to MDP105. Analysis of enzymatic active sites of the predicted proteins revealed that 94 of them are serine protease-like proteins and the remaining 11 are cysteine protease-like proteins. Of the 94 serine protease-like proteins,

17131 were identified to be putative trypsins, 18 putative chymotrypsins, 29 trypsin/chymotrypsin

172 homologs (Kwon et al., 2000), and 16 truncated proteins that could not be classified (Figure S1).

173 Among the 11 cysteine protease-like proteins, seven of them possess all functionally critical 174 residues (see below) and therefore were taken as putative cysteine proteases, whereas the other 175 four are homologs that do not have all the functionally important residues conserved (Figure S1). 176 sequences from Drosophila melanogaster revealed five major groups (Figure 1A). All putative

178 Hessian fly chymotrypsins are clustered within groups 1 and 2. Thirteen putative Hessian fly 179 trypsins are in group 1, while the remaining 18 trypsins are scattered into the other four groups. 180 The putative Hessian fly cysteine-proteases were analyzed along with known cysteine proteases 181 from other insects (Figure 1B). Hessian fly cysteine proteases are clustered with Drosophila 182 cysteine proteases except MDP95, MDP96, and MDP97, which either form an independent 183 group or clustered together with cysteine proteases from other insects. 
Other characteristics of the putative trypsins, chymotrypsins, and cysteine proteases are

185 given in Table 1, including predicted molecular weight (MW), isoelectric point (pI), number of amino acids, and first hit information of BLAST searches (GenBank accession no., scores, Evalue, and name of the organism). Ten of the 31 putative trypsin precursors are full length (starting with methionine), and 9 of them were predicted to have 17-23 residue signal peptide, suggesting that most trypsins are not membrane-bound. Similarly, most putative chymotrypsin precursors have 19-21 residue signal peptide, and most cysteine-protease precursors have 16-22 residue signal peptide.

\subsection{Putative trypsin genes}

By using blast similarity search of GenBank and MotifScan and ScanProsite tools, sequence pattern and functional motifs for trypsin were revealed, including charge relay system or active site residues H, D. and S, and three pairs of cysteines for disulfide bonds to confirm the trypsin gene identity. An alignment of the 31 putative trypsins is shown in Figure $2 \mathrm{~A}$. The specificity determinant residue $\mathrm{D}^{312}$ for trypsins is conserved in all proteins. The catalytic triad $\mathrm{H}^{104}, \mathrm{D}^{185}$, and $\mathrm{S}^{318}$ residues are also conserved in all members. The overall sequence identities among the putative trypsins are very low. The two most closely related proteins, MDP-3 and MDP-5, exhibit 61.3\% sequence identity (Table S2). The two most diversified proteins, MDP58 and MDP-79, exhibit only $20.7 \%$ sequence identity. The majority of members share $25-$ $35 \%$ identity.

\subsection{Putative chymotrypsin genes}

Chymotrypsins share major sequence patterns and functional motifs with trypsins. The major difference between a trypsin and a chymotrypsin is that trypsins are characterized by the 
206 presence of specificity determinant residue $\mathrm{D}^{312}$ (Figure 2A), while chymotrypsins usually have 207 G or S at corresponding position (residue 298, Figure 2B) (Hedstrom et al., 1992; Wang et al., 208 1993). Trypsins cleave the protein chain on the carboxyl side of arginine or lysine, whereas 209 chymotrypsin cleaves on the carboxyl side of aromatic amino acids (Terra and Ferreira, 1994). 210 An alignment of the 18 putative chymotrypsins is given in Figure 2B. The catalytic triad $\mathrm{H}^{119}$, $211 \mathrm{D}^{185}$, and $\mathrm{S}^{304}$ are conserved in all putative chymotrypins. However, the specificity determinant

212 residue $\mathrm{G} / \mathrm{S}^{298}$ is not found in some members at the exact position in the alignment. Specifically, 213 the specificity determinant residue is $\mathrm{Y}$ in MDP-15 and MDP-16, F residue in MDP-17, and $\mathrm{H}$ 214 residue in MPD-84 and MDP-85. These five proteins are either chymotrypsin homologs without 215 enzymatic activity, or the specificity determinant residue is located in nearby positions, which 216 were not correctly positioned in the alignment. Like trypsins, the putative chymotrypsins are 217 also highly diversified. The two most closely related proteins, MDP-15 and MDP-16, share 218 81.5\% sequence identity (Table S3). The two most diversified proteins, MDP-7 and MDP-85, 219 share only $18.3 \%$ identity. The majority of the proteins share $22-32 \%$ sequence identity.

\subsection{Putative cysteine-protease genes}

222 physiological protein breakdown, but they are optimally active in the slightly acidic condition 223 (Turk et al., 2001). Cystene proteases also have different active site residues compared to those 224 in trypsins and chymotrypsins. By using MotifScan and ScanProsite, the identity of several 225 cysteine proteases were confirmed with the presence of active residue cysteine and two 226 additional active site residues, histidine and asparagines (Dufour, 1988). An alignment among 227 the seven putative cysteine-proteases is given in Figure $2 \mathrm{C}$. The alignment at the N-terminal 228 region exhibits very different sequences with little similarity. The C-terminal region, in 
229 comparison, is relatively conserved. The three important residues $\mathrm{C}^{391}, \mathrm{H}^{570}$, and $\mathrm{N}^{591}$ at the 230 active site are located at the C-terminal region and are conserved in all members. Sequence 231 identity between these proteins ranged from 22 to $64 \%$ with the exception of MDP-99 and MDP232 100, which are identical (Table S4). MDP-99 and MDP-100 are encoded by two tandem genes 233 (AEGA01013770).

\subsection{Stage-specific expression of trypsin, chymotrypsin, and cysteine protease genes} transcript abundance with different protease genes in Hessian flies at different developmental

237 stages (Figure 3). There were only a few genes, such as MDP-95 and MDP-100 (Figure 3C), 238 whose transcripts were relatively equally distributed in larvae, pupae and adults. The majority of 239 the genes exhibited higher levels of transcripts at a certain stage(s) of fly development. Overall, more genes exhibited higher transcript levels in 3- to 12-day old larvae and fewer genes

241 exhibited higher transcript levels in adults and 1-day old larvae.

\subsection{Tissue-specific expression of trypsin, chymotrypsin, and cysteine protease genes}

Since the Hessian fly larva is the only feeding stage and 3-day-old larvae are most active,

244 the tissues of 3-day larvae including the gut, salivary glands, fat bodies, Malphigian tubules, and 245 the remaining carcass were dissected for RT-PCR analyses. The results of larval tissue analysis 246 also revealed different patterns of transcript abundance with the different protease genes in 247 different tissues (Figure 4). For the trypsin genes, MDP48 was exclusively expressed in the 248 larval gut. MDP9, MDP3, MDP72, MDP51, MDP24, and MDP23 exhibited higher transcript 249 levels in gut tissues than in other tissues. MDP90, MDP5, and MDP57 exhibited higher 250 transcript levels in both the gut and salivary gland samples. For chymotrypsin genes, MDP1, 
251 MDP8, and MDP2 exhibited higher transcript levels in the gut sample than in other tissues.

252 MDP7, MDP20, and MDP21 exhibited higher transcript levels in both the gut and salivary gland

253 samples than in other tissues. None of the cysteine protease genes exhibited predominant

254 abundance in the gut or salivary gland samples.

255

256

257

258

259

260

261

262

263

264

265

266

267

268

269

270

271

272

273

\subsection{Host plant genotypes affect the expression of several protease genes}

To examine if plant defense affects the expression of protease genes, Hessian fly larvae were reared on the near-isogenic lines Newton and Molly. Newton is a Hessian fly susceptible wheat line with no Hessian fly resistance genes, while Molly is a back-cross offspring of Newton, but contains the resistance gene H13 (Patterson et al., 1994). Hessian fly larvae of avirulent biotypes die without development in resistant Molly plants. The majority of protease genes showed no significant differences in transcript abundance in Hessian fly larvae reared on susceptible Newton and resistant Molly (data not shown). However, seven protease genes exhibited increased transcript abundance and six protease genes exhibited decreased transcript abundance in larvae feeding on resistant Molly plants (Figure 5).

The protease genes with increased transcript levels in larvae feeding in resistant Molly plants included genes encoding trypsins MDP3, MDP9, and MDP23; Chymotrypsins MDP20 and MDP21; and cysteine proteases MDP99 and MDP104 (Figure 5A). For the three trypsin genes, MDP3 and MDP9 were expressed at low levels in larvae feeding in susceptible Newton, but transcript levels increased approximately three-fold in both 1-day and 3-day old larvae feeding in resistant Molly. For MDP23, transcript was essentially undetected in larvae feeding in susceptible plants, but was abundantly expressed in both 1-day and 3-day old larvae feeding in resistant plants. For the chymotrypsin genes, both MDP20 and MDP21 were undetectable by RT-PCR in larvae feeding on susceptible Newton, but were transiently upregulated to high levels 
274 in 1-day old larvae feeding in resistant Molly plants. For the cysteine protease genes, transcript

275 for MDP99 was not detectable in larvae feeding in susceptible Newton plants, but was

276 upregulated to high level in larvae feeding in resistant plants. The transcript of MDP104 was

277 expressed at low level in 1- and 3-day old larvae feeding in susceptible plants, and was

278 upregulated to higher levels in larvae feeding in resistant plants. The protease genes with

279 decreased transcript abundance in larvae feeding in resistant plants included genes encoding

280 trypsins $M D P 12, M D P 24$, and $M D P 33$; and chymotrypsins $M D P 8, M D P 15$, and $M D P 16$ (Figure

281 5B). These protease genes were expressed abundantly at least in 3-day old larvae feeding in

282 susceptible plants, but were essentially undetectable in larvae feeding in resistant plants.

\section{Discussion}

Our main interest was to identify proteases involved in the digestive system of Hessian

286 fly larvae, the only feeding stage of the insect. Stage- and tissue-specific expression analyses

287 revealed that trypsins MDP3, MDP5, MDP9, MDP24, MDP48, MDP51, MDP57, MDP61,

288 MDP71, and MDP90, chymotrypsins MDP1, MDP7, MDP8, MDP18, MDP19, and MDP20, and

289 cysteine proteases MDP95 and MDP104 are candidates as digestive enzymes in Hessian fly

290 larvae. Interestingly, the majority (11 out 16) of the putative digestive trypsins and

291 chymotrypsins belong to the phynogentic group 1, and the remaining belongs to group 5 (Figure

292 1A). Group 1 contains the largest number of Hessian fly trypsins and chymotrypsins. We

293 speculate that the expansion of group 1 is related with Hessian fly adaptation to changes in host

294 plants. Consistent with this speculation, all trypsin and chymotrypsin genes except MDP33 that

295 were either up- or down-regulated on resistant host plants belong to this group (Figure 1A).

296 Phytophagous insects alter the expression of different digestive enzymes in response to plant 
297 defense (Bown et al., 1997). Wheat plants with an effective Hessian fly-resistance gene produce

298 elevated levels of different types of protease inhibitors in response to Hessian fly attack, whereas

299 the expression of inhibitor genes is suppressed in susceptible plants (Liu et al., 2007; Wu et al.,

300 2008). Therefore, genes encoding digestive proteases may exhibit differential expression

301 patterns in Hessian fly larvae feeing in susceptible plants from those feeding in resistant plants,

302 potentially due to the change in concentrations of protease inhibitors in host plants. The change

303 in expression levels of these protease genes could be due to a reprogramming of digestive arsenal

304 in the Hessian fly larval gut in response to elevated levels of protease inhibitors produced in

305 resistant plants. The impact of host genotypes on the expression levels of these protease genes

306 further indicates that these genes encode digestive proteases.

Interestingly, our data also indicate that the identified Hessian fly protease genes are

308 highly diversified. The majority of protease genes share sequence identity of less than $35 \%$

309 (Tables S2, S3, S4). With the exception of two identical cysteine proteases, MDP-99 and MDP-

310100 , the highest amino acid sequence identity shared by two putative trypsins is $61.3 \%$ (MDP-3

311 and MDP-5); and the highest amino acid sequence identity shared by two identified

312 chymotrypsins is $81.5 \%$ (MDP-15 and MDP-16). This observation is far different from an

313 earlier analysis of protease transcripts from the Hessian fly larval gut (Zhu et al., 2005), which

314 identified many transcripts encoding trypsins and chymotrypsins that share over $90 \%$ amino acid

315 identity. Large numbers of transcripts encoding very similar, but distinct proteins has also been

316 found in other insects (Zhu et al., 2003; Coates et al., 2006). These observations suggest that

317 similar, but distinct trypsins and chymotrypsins revealed from transcriptomic analyses are

318 encoded by different alleles instead of similar genes. An insect population that keeps a large

319 number of different protease gene alleles must gain certain adaptive advantages. For 
320 phytophagous insects, the adaptive advantage of maintaining allelic diversity in digestive

321 protease genes is most likely towards adaptation to possible changes in protease inhibitors in host

322 plants.

Our data suggested that two cysteine protease genes, MDP95 and MDP104, may also

play a role in digestion under certain conditions. The expression of these two genes was affected

325 by host genotypes. Specifically, they were upregulated in larvae feeding in resistant plants. In

326 addition, transcripts of these two genes were identified in cDNA libraries from gut tissue (Zhang

327 et al., 2010). However, these two genes were also expressed in other tissues and in non-feeding

328 stages of the insect (Figures 3 and 4), indicating other functions. So far, cysteine proteinases

329 have been found in the midgut lumen (acting as digestive enzymes) only in hemipterans and

330 coleopterans. Therefore, the digestive function of cysteine proteases in the gut of gall midges

331 remains to be determined experimentally.

Ever since the discovery of protease inhibitor induction following insect attack by Ryan

333 (1973), protease inhibitors have become targets of bioengineering for arthropod pest control

334 (Lawrence and Koundal, 2002; Schlüter et al., 2010). Yet so far, no commercial cultivar with an 335 engineered protease inhibitor has achieved effective, long-lasting defense to insect pests in the

336 field. The difficulty in doing so comes from the multiplicity of diverse protease genes and their

337 dynamic changes in response to elevated inhibitors in host plants. A better understanding of

338 genome-wide composition of digestive proteases and the regulation of the expression of the

339 encoding genes may help to optimize the strategy for engineering protease inhibitors. The

340 availability of whole genome sequences of an increasing number of insect species provides us an

341 opportunity to study the insect gut digestive enzymes and their interactions with host inhibitors

342 globally, comparatively, and comprehensively. The identification of serine-protease and 
343 cysteine-protease genes in the Hessian fly genome, and the determination of their expression 344 profiles in different developmental stages and different fly tissues of the insect provide the 345 foundation for further characterization of Hessian fly digestive proteases and their interactions 346 with host plants. 


\section{Acknowledgment}

This contribution No. for this paper is 13-052-J from the Kansas Agricultural Experiment

349 Station. Hessian fly voucher specimens (No. 150) are located in the KSU Museum of

350 Entomological and Prairie Arthropod Research, Kansas State University, Manhattan, Kansas.

351 The authors want to thank Drs. Kun Yan Zhu and Michael Smith for reviewing an earlier version

352 of the manuscript. The research was partially supported by a grant from the U.S. Department of

353 Agriculture (USDA NIFA 2010-03741) and a grant from the National Natural Sciences

354 Foundation of China (grant no.30800105).

355

356 


\section{References}

Ahn, J.E., Salzman, R.A., Braunagel, S.C., Koiwa, H., Zhu-Salzman, K., 2004. Functional roles of specific bruchid protease isoforms in adaptation to a soybean protease inhibitor. Insect Mol. Biol. 13, 649-657.

Barrett, A.J., Rawlings, N.D., Woessner, J.F., 1998. Handbook of Proteolytic Enzymes. Academic Press. New York.

Bjellqvist, B.,Hughes, G.J., Pasquali, Ch., Paquet, N., Ravier, F., Sanchez, J.-Ch., Frutiger, S. \& Hochstrasser, D.F.(1993) The focusing positions of polypeptides in immobilized pH gradients can be predicted from their amino acid sequences. Electrophoresis 14, 1023-1031.

Bown, D.P., Wilkinson, H.S. \& Gatehouse, J.A., 1997. Differentially regulated inhibitorsensitive and insensitive protease genes from the phytophagous insect pest, Helicoverpa armigera, are members of complex multigene families. Insect Biochem. Mol. Biol. 27, 625638.

Brioschi, D., Nadalini, L.D., Bengtson, M.H., Sogayar, M.C., Moura, D.S., Silva-Filho, M.C. 2007. General up regulation of Spodoptera frugiperda trypsins and chymotrypsins allow its adaptation to soybean proteinase inhibitor. Insect Biochem. Mol. Biol. 37, 1283-1290.

Buntin, G.D., 1999. Hessian fly (Diptera: Cecidomyiidae) injury and loss of winter wheat grain yield and quality. J. Econ. Entomol. 92, 1190-1197.

Burgess, E.P.J., Main, C.A., Stevens, P.S., Christeller, J.T., Gatehouse, A.M.R., Laing, W.A., 1994. Effects of protease inhibitor concentration and combinations on the survival, growth and gut enzyme activities of the blackfield cricket, Teleogryllus commodus. J. Insect Physiol. 40, 803-811. 
379 Chen, M.S., 2008. Inducible direct plant defense against insect herbivores. Insect Sci.15, 101-

380

381

382

383

384

385

386

387

388

389

390

391

392

393

394

395

396

397

398

399

400

401

114.

Chen, M.S., Echegaray, E., Whitworth, R.J., Wang, H., Sloderbeck, P.E., Knutson, A., Giles, K.L. 2009. Virulence analysis of Hessian fly (Mayetiola destructor) populations from Texas, Oklahoma, and Kansas. J. Econ. Entomol. 102, 774-780.

Coates, B.S., Hellmich, R.L., Lewis, L.C., 2006. Sequence variation in trypsin- and chymotrypsin-like cDNAs from the midgut of Ostrinia nubilalis: methods for allelic differentiation of candidate Bacillus thuringiensis resistance genes. Insect Mol. Biol. 15, 1324.

Dufour, E., 1988. Sequence homologies, hydrophobic profiles and secondary structures of cathepsins B, H and L: comparison with papain and actinidin. Biochimie 70, 1335-1342.

Eberhard, S.H., Hrassnigg, N., Crailsheim, K., Krenn, H.W., 2007. Evidence of protease in the saliva of the butterfly Heliconius melpomene (L.) (Nymphalidae, Lepidoptera). J. Insect Physiol. 53, 126-131.

Felsenstein, J., 1985. Confidence limits on phylogenies: an approach using the bootstrap. Evolution 39, 783-791.

Gattiker A., Gasteiger E., Bairoch A., 2002. ScanProsite: a reference implementation of a PROSITE scanning tool. Appl. Bioinformatics 1, 107-108.

(http://prosite.expasy.org/scanprosite/)

Habib, H., Fazili K.M., 2007. Plant protease inhibitors: a defense strategy in plants. Biotech. Mol. Biol. Rev. 2, 68-85.

Hall, T.A., 1999. BioEdit: a user-friently biological sequence alignment editor and analysis program for Windows 95/98/NT. Nucl. Acid. Symp. Series 41, 95-98. 
Hatchett, J.H., Starks, K.J., Webster, J.A., 1987. Insect and mite pests of wheat. In: Wheat and Wheat improvement. Agronomy Monograph No. 13, 625-675.

Hedstrom, L., Szilagyi, L., Rutter, W.J., 1992. Converting trypsin to chymotrypsin: the role of surface loops. Science 255, 1249-1253.

Holt C., Yandell M., 2011. MAKER2: an annotation pipeline and genome-database management tool for second-generation genome projects. BMC Bioinform. 12, 491.

Jongsma, M.A., Beekwilder, J., 2011. Co-evolution of insect proteases and plant protease inhibitors. Curr. Protein Pept. Sci. 12, 437-447.

Jongsma M.A., Bakker P.L., Peters J., Bosch D., and Stiekema W.J.,1995. Adaptation of Spodoptera exigua larvae to plant proteinase inhibitors by induction of gut proteinase activity insensitive to inhibition, Proc. Natl. Acad. Sci. USA 92, 8041-8045.

Kwon, T.H., Kim, M.S., Choi, H.W., Joo, C.H., Cho, M.Y. and Lee,B.L., 2000. A masqueradelike serine proteinase homologue is necessary for phenoloxidase activity in the coleopteran insect, Holotrichia diomphalia larvae. Eur. J. Biochem. 267, 6188-6196.

Larkin, M.A., Blackshields, G., Brown, N.P., Chenna, R., McGettigan, P.A., McWilliam, H., Valentin, F., Wallace, I.M., Wilm, A., Lopez, R., Thompson, J.D., Gibson, T.J., Higgins, D.G. 2007. Clustal W and Clustal X version 2.0. Bioinformatics 23(21), 2947-2948.

Lawrence, P.K., Koundal, K.P., 2002. Plant protease inhibitors in control of phytophagous insects. Electronic J. Biotech. 5, 93-103.

Liu, X.L., Bai, J., Huang, L., Zhu, L., Liu, X., Weng, N., Reese, J.C., Harris, M., Stuart, J.J., Chen, M.S., 2007. Gene expression of different wheat genotypes during attack by virulent and avirulent Hessian fly (Mayetiola destructor) larvae. J. Chem. Ecol. 33, 2171-2194. 
424 Lopes, A.R., Juliano, M.A., Marana, S.R., Juliano, L., Terra, W.R., 2006. Substrate specificity of 425 insect trypsins and the role of their subsites in catalysis. Insect Biochem. Mol. Biol. 36, 130140.

427 Matsumoto, I., Watanabe, H., Abe, K., Arai, S., Emori, Y., 1995. A putative digestive cysteine proteinase from Drosophila melanogaster is predominantly expressed in the embryonic and larval midgut. Eur. J. Biochem. 227, 582-587.

Mazumdar-Leighton, S. \& Broadway, R.M., 2001. Identification of six chymotrypsin cDNAs from larval midguts of Helicoverpa zea and Agrotis ipsilon feeding on the soybean (Kunitz) trypsin inhibitor. Insect Biochem. Mol. Biol. 31, 633-644.

Miles, P.W., 1999. Aphid saliva. Biol. Rev. 74, 41-85.

Moura, D.S., Ryan, C.A., 2001. Wound-inducible proteinase inhibitors in pepper. Differential regulation upon wounding, systemin and methyl jasmonate. Plant Physiol. 126 (1), 289-298.

Murdock, L.L., Shade, R.E., Pomeroy, M.A., 1988. Effects of E-64, acysteine proteinaseinhibitor, on cowpea weevil growth, development, and fecundity. Environ. Entomol. 17, 467-469.

Neurath, H., 1999. Proteolytic enzymes, past and future. Proc. Natl. Acad. Sci. USA. 96, $10962-$ 10963.

Neurath, H., Walsh, K.A., 1976. Role of proteolytic enzymes in biological regulation (a review). Proc Natl Acad Sci USA.73, 3825-3832.

Patterson. F.L., Mass. F.B. III, Foster. J.E., Ratcliffe. R.H., Cambron. S., Safranski. G., Taylor. P.L., Ohm. H.W., 1994. Registration of eight Hessian fly resistant common winter wheat germplasm lines (Carol, Erin, Flynn, Iris, Joy, Karen, Lola, and Molly). Crop Sci. 34, 315316.

Pauly, P.J., 2002. Fighting the Hessian fly. Environ. Hist. 7, 385-507. 
Pechan, T., Cohen, A., Williams, W. P., Luthe, D. S., 2002. Insect feeding mobilizes a unique plant defense protease that disrupts the peritrophic matrix of caterpillars. Proc. Natl. Acad. Sci. USA 99, 13319-13323.

Petersen, T.N., Brunak, S., von Heijne, G., Nielsen, H., 2011. SignalP 4.0: discriminating signal peptides from transmembrane regions. Nature Methods, 8, 785-786. http://www.cbs.dtu.dk/services/SignalP/

Ross, J., Jiang, H., Kanost, M.R., Wang, Y., 2003. Serine proteases and their homologs in the Drosophila melanogaster genome: an initial analysis of sequence conservation and phylogenetic relationships. Gene 304, 117-131.

Ryan, C.A., 1973. Proteolytic enzymes and their inhibitors in plants. Annu. Rev. Plant Physiol. 24, 173-96

Sato, P.M., Lopes, A.R., Juliano, L., Juliano, M.A., Terra, W.R., 2008. Subsite substrate specificity of midgut insect chymotrypsins. Insect Biochem. Mol. Biol. 38, 628-633.

Schlüter, U., Benchabane, M., Munger, A., Kiggundu, A., Vorster, J., Goulet, M.-C., Cloutier, C., Michaud, D., 2010. Recombinant protease inhibitors for herbivore pest control: a multitrophic perspective. J. Exp. Bot. 61, 4169-4183.

Shukle, R.H., Murdock, L.L., Gallun, R.L., 1985. Identification and partial characterization of a major gut proteinase from larvae of the Hessian fly, Mayetiola destructor (Say) (Deptera: Cecidomyiidae).Insect Biochem. 15, 93-101.

Stuart J.J., Chen M.S., Shukle R., Harris M.O., 2012. Gall Midges (Hessian Flies) as Plant Pathogens. Annu. Rev. Phytopathol. 50, 17.1-17.19.

Tamura K., Nei M., Kumar S., 2004. Prospects for inferring very large phylogenies by using the neighbor-joining method. Proc. Natl. Acad. Sci. 101, 11030-11035. 
471 Tamura, K., Peterson, D., Peterson, N., Stecher, G., Nei, M., Kumar, S., 2011. MEGA5:

472

473

474

475

476

477

478

479

480

481

482

483

484

485

486

487

488

489

490

491

492

493

Molecular Evolutionary Genetics Analysis using Maximum Likelihood, Evolutionary

Distance, and Maximum Parsimony Methods. Mol. Biol. Evol. 28, 2731-2739.

Terra, W.R., Ferreira, C., 1994. Insect digestive enzymes: properties, compartmentalization and function. Comp. Biochem. Physiol. 109B,1-62.

Turk, V., Turk, B., Turk, D., 2001. Lysosomal cysteine proteases: facts and opportunities.

EMBO J. 20, 4629e4633.

Wang, S., Magoulas, C., Hickey, D.A., 1993. Isolation and characterization of a full-length trypsin-encoding cDNA clone from the lepidopteran insect Choristoneura fumiferana. Gene $136,375-376$.

Wright, M.K., Brandt, S.L., Coudron, T.A., Wagner, R.M., Habibi, J., Backus, E.A., Huesing, J.E., 2006. Characterization of digestive proteolytic activity in Lygus hesperus Knight (Hemiptera : Miridae). J. Insect Physiol. 52, 717-728.

Wu J.X., Liu X.M., Zhang S.Z., Y.C. Zhu, Whitworth R.J., Chen M.S., 2008. Differential responses of wheat inhibitor-like genes to Hessian fly, Mayetiola destructor, attacks during compatible and incompatible interactions. J. Chem. Ecol. 34, 1005-1012.

Yusim K.S.J., Honeyborne I., Calef C., Goulder P.J., Korber B.T., 2004. Enhanced motif scan: A tool to scan for HLA anchor residues in proteins. Los Alamos: Theoretical Biology and Biophysics Group, Los Alamos National Laboratory. pp. 25-36. Publication number LAUR 04-8162. pp. (http://myhits.isb-sib.ch/cgi-bin/motif scan)

Zhang, S.Z., Shukle, R., Mittapalli, O., Zhu, Y.C., Reese, J.C., Wang, H.Y., Hua, B.Z., Chen ,M.S., 2010. The Gut Transcriptome of a Gall Midge, Mayetiola destructor. J. Insect Physiol. 56, 1198-1206. 
494 Zhu, Y.C., Liu, X., Maddur, M., Oppert, B., Chen, M.S., 2005. Cloning and characterization of 495 chymotrypsin- and trypsinlike cDNAs from the gut of the Hessian fly [Mayetiola destructor (Say)]. Insect Biochem. Mol. Biol. 35, 23-32.

497 Zhu Y.C., Zeng F.R., Oppert B., 2003. Molecular cloning of trypsin-like cDNAs and

498 comparison of proteinase activities in the salivary glands and gut of the tarnished plant bug 499 Lygus lineolaris (Heteroptera: Miridae). Insect Biochem. Mol. Biol. 33, 889-899.

500 


\section{Figure Legends:}

502

503

504

505

506

507

508

509

510

511

512

513
Figure 1. Phylogenetic analyses. A. A phylogenetic tree of identified Hessian fly trypsins and chymotrypsins along with serine proteinases from Drosophila melanogaster. Names in red color are trypsins, names in blue are chymotrypsins, and names in black are serine proteinases from Drosophila. B. A phylogenetic tree of identified putative Hessian fly cysteine-protease proteases along with known cysteine proteases from other insects. Hessian fly cysteine proteases are in pink color and the cysteine proteases from other insects are in black color. Dme, Tmo, Dro, Sze, Bmo, Mpe, Rpr, Foc, Hpo, Dvi, Lde, $\mathrm{Pco}$, and $\mathrm{Cma}$, represent cysteine proteases from Drosophila melanogaster, Tenebrio molitor, Delia radicum, Sitophilus zeamais, Bombyx mori, Myzus persicae, Rhodnius prolixus, Frankliniella occidentalis, Hypera postica, Diabrotica virgifera, Leptinotarsa decemlineata, Phaedon cochleariae, and Callosobruchus maculates, respectively.

Figure 1A
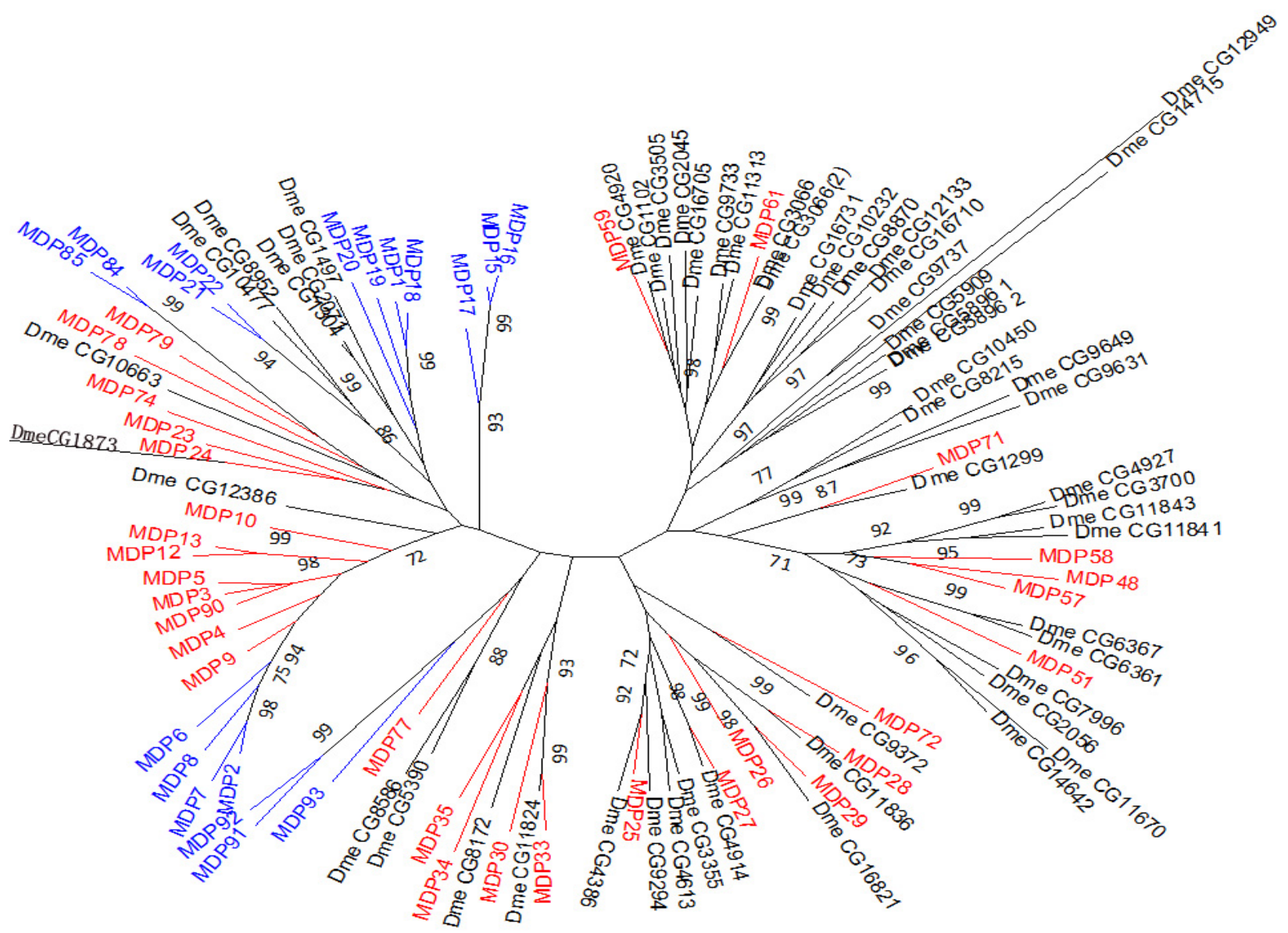

514 
517 Figure 1B

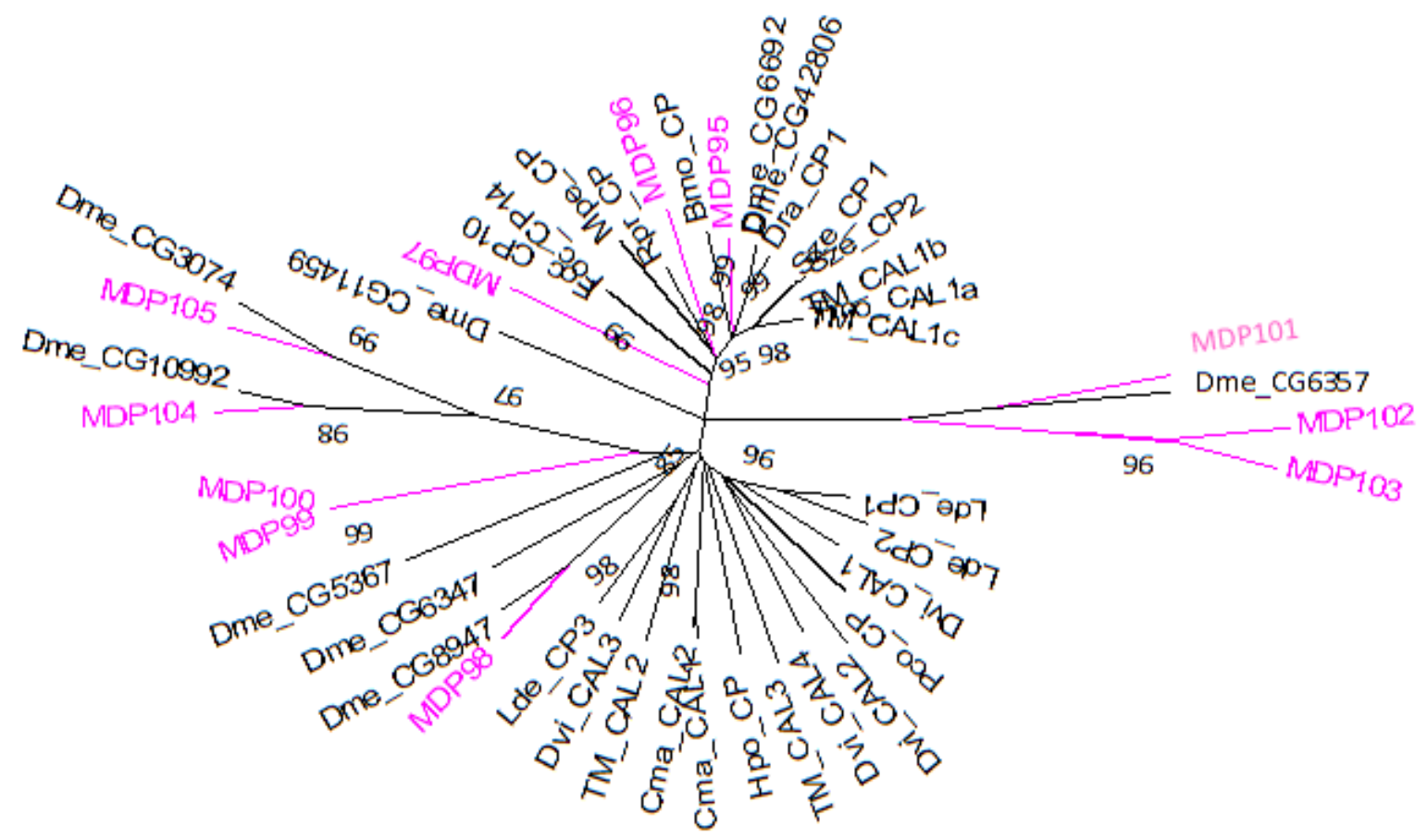

518 
Figure 2. Amino acid alignments of different types of proteases. A. Alignment of 31 identified putative trypsins. Functionally important residues $\mathrm{H}, \mathrm{D}$, and $\mathrm{S}$ (active sites) are boxed. Cysteine residues corresponding to the sites of the predicted disulfide bridges are marked with arrows at the bottom. The trypsin specificity determinant residue is indicated with $(\downarrow)$ on the top of the alignment. The activation site (consensus K/R-IVGG at position 41 ) is conserved in most of the putative trypsins. Hyphens represent alignment gaps. Trypsins MDP3, MDP4, MDP5, MDP9, MDP10, MDP12, MDP23, MDP24, MDP79, and MDP90 are full length and each has a predicted signal peptide. B. An alignment of the 18 identified putative chymotrypsins. Functionally important residues $\mathrm{H}, \mathrm{D}$, and $\mathrm{S}$ (active sites) are boxed. Cysteine residues corresponding to the sites of the predicted disulfide bridges are marked with arrows at the bottom. Chymotrypsin specificity determinant residue is indicated with ( $\bullet$ ) on the top of the alignment. The activation site (consensus K/R-IVGG at position 65) is partially conserved in most of the putative trypsins. Hyphens represent alignment gaps. MDP1, MDP2, MDP6, MDP7, MDP8, MDP15, MDP16, MDP17, MDP18, MDP19, MDP21, MDP22, MDP84, and MDP85 are full length and each has a typical secretion signal peptide. C. An alignment of the seven putative cysteine-proteases. All putative cysteine proteases are full length and each has a typical secretion signal peptide.

Figure 2A

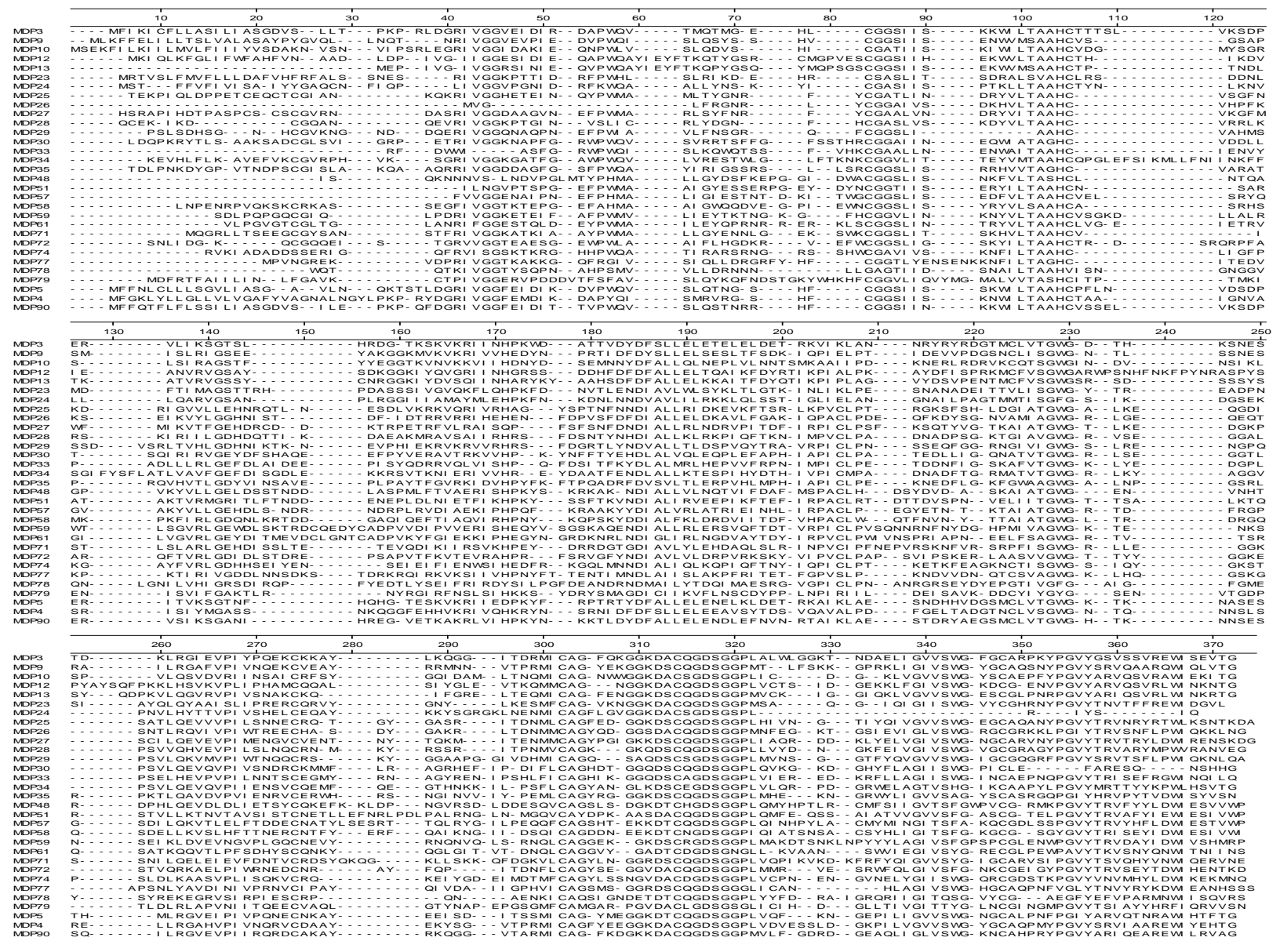



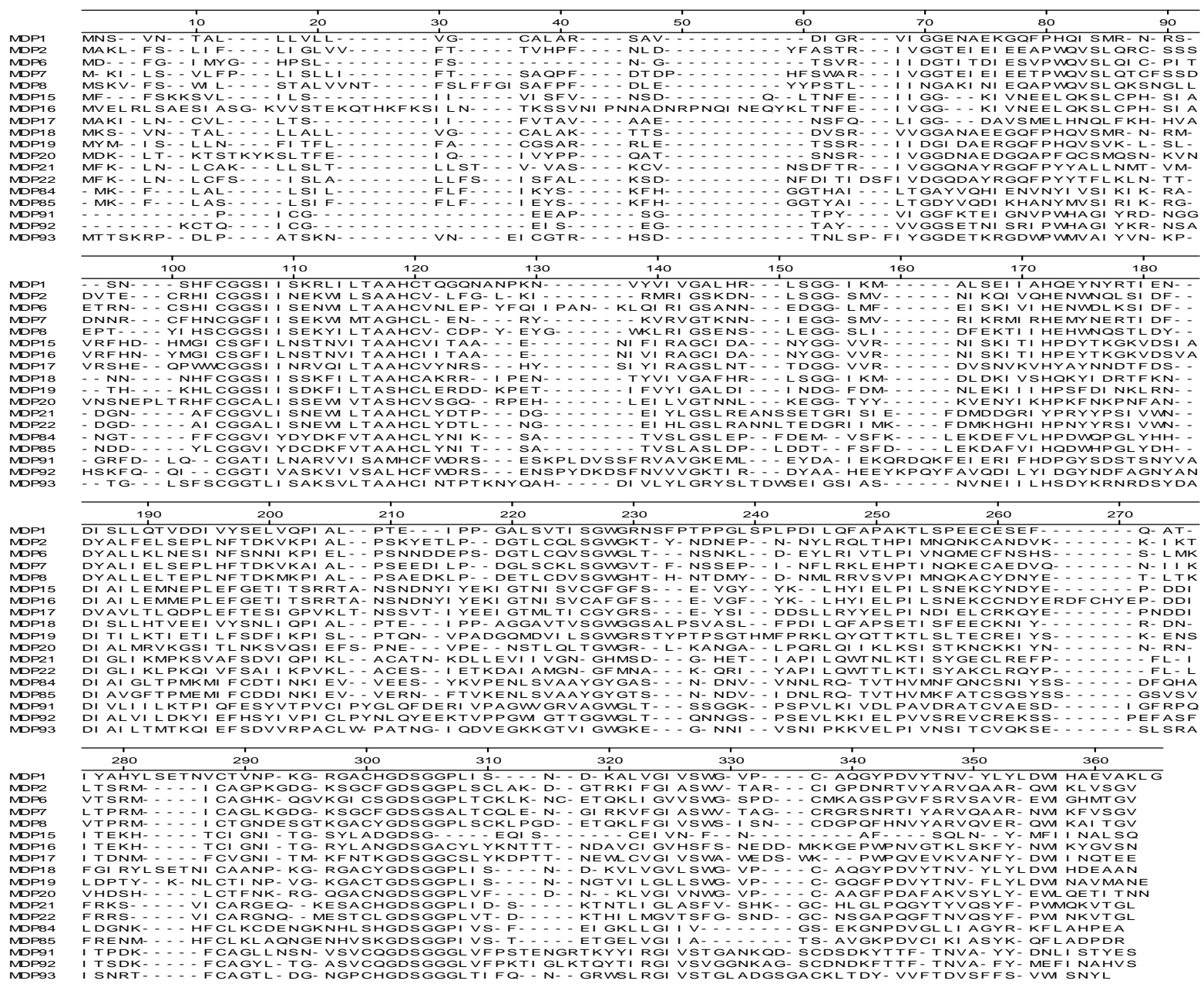

539

540

541 
Figure 3. RT-PCR analyses of various protease transcripts in insects at different developmental stages.

543 A. Transcript abundance of putative trypsin genes. B. Transcript abundance of putative chymotrypsin 544 genes. C. Transcript abundance of putative cysteine protease genes. $1 \mathrm{~L}, 3 \mathrm{~L}, 6 \mathrm{~L}, 12 \mathrm{~L}$, P, and $\mathrm{A}$ on the top 545 of images represent one-day, 3-day, 6-day, and 12-day old larvae, pupae, and adults, respectively. Gene 546 names are given on the left of the images. Transcript abundance is shown in grey scale, with darker 547 rectangles indicating higher transcript abundance.

548

A

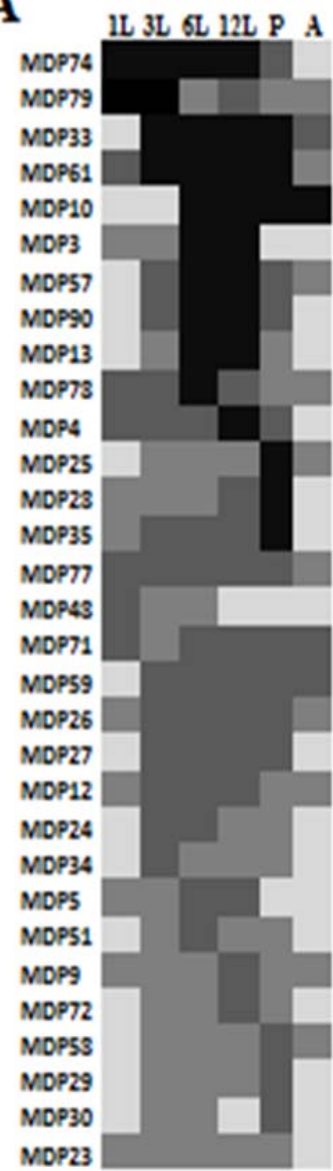

B

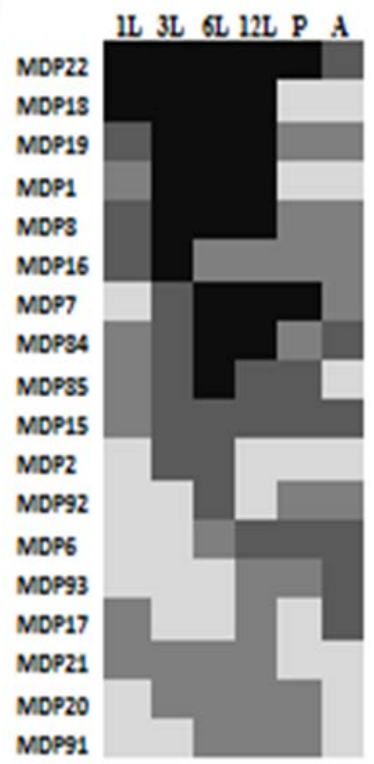

C

MOP95

MDP100

MDP104

NOP9s

MOP96

NDP97

Nop99

IL $3 L$ G $12 \mathrm{~L} P$ A 
Figure 4. RT-PCR analyses of various protease transcripts in different tissues of three-day old larvae.

551 A. Transcript abundance of putative trypsin genes. B. Transcript abundance of putative chymotrypsin 552 genes. C. Transcript abundance of putative cysteine protease genes. MG, SG, FB, MT, and CC on the top 553 of images represent mid-gut, salivary gland, fat body, Malphagian tubule, and the remaining carcass, 554 respectively. Gene names are given on the left of the images. Transcript abundance is shown in grey 555 scale, with darker rectangles indicating higher transcript abundance.

A

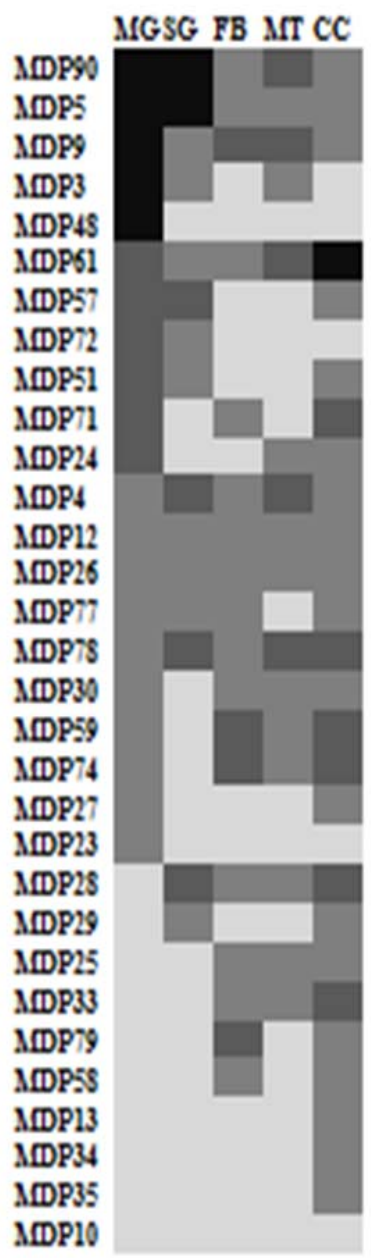

B

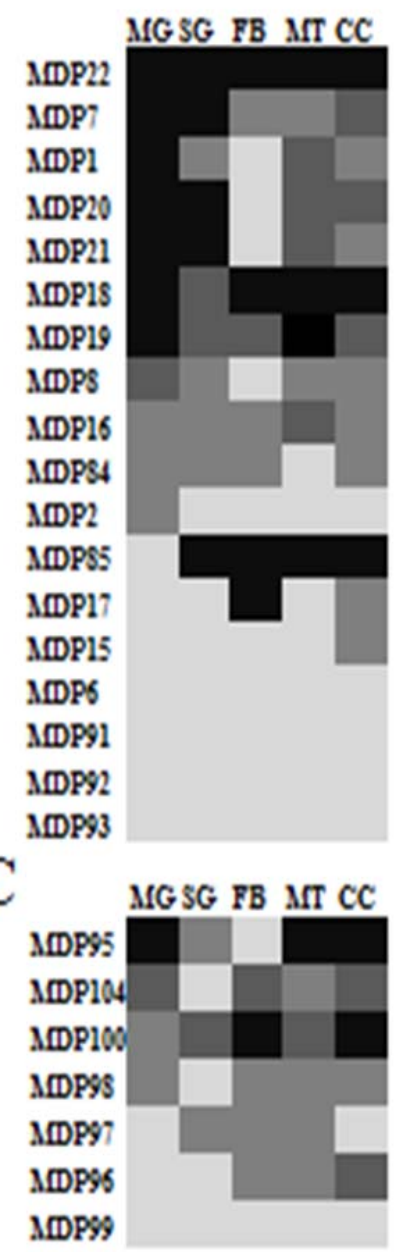


Figure 5. qPCR analyses of changes in transcript abundance of selected protease genes in Hessian fly larvae feeding in plants of different genotypes. A. Increased transcript abundance of protease genes in larvae feeding in fly resistant Molly (M) plants that contains the resistance gene $\mathrm{H} 13$ in comparison with that in larvae feeding in susceptible isogenic Newton (N) plants (Patterson et al., 1994). B. Decreased transcript abundance of protease genes in larvae feeding in resistant Molly plants. The numbers 1 and 3 under the graphs represent samples from 1-day and 3-day larvae, respectively.

564

A

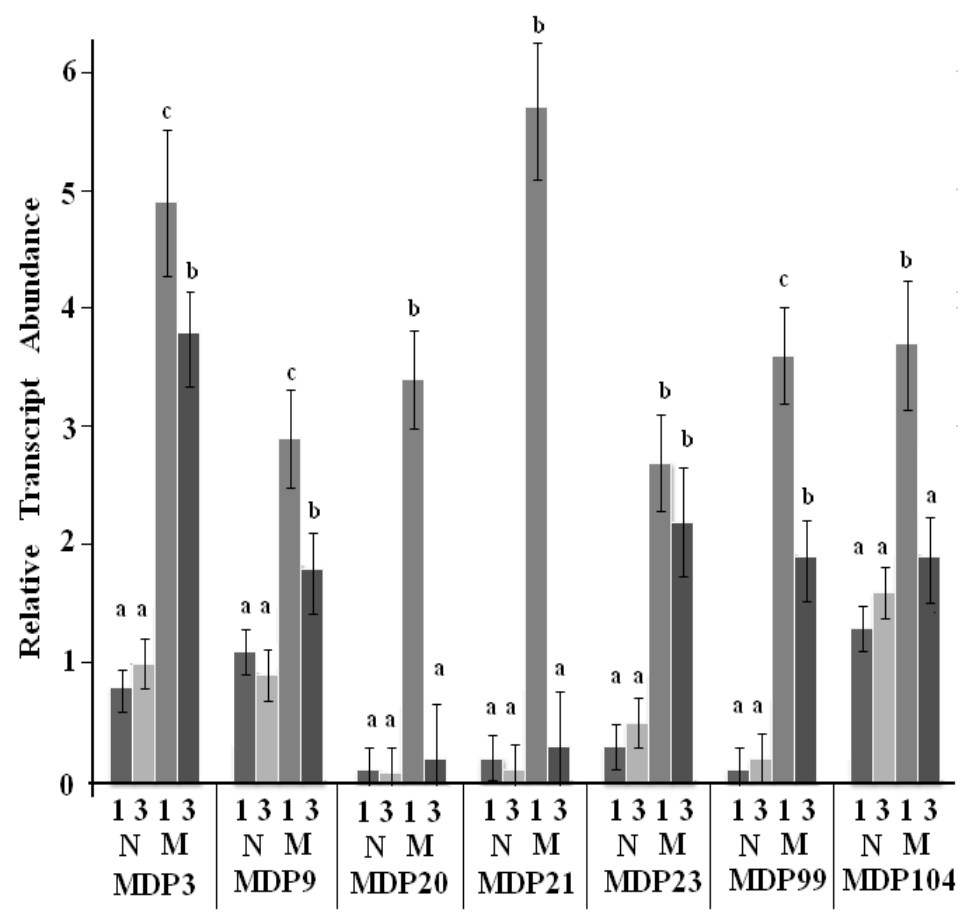

566

B

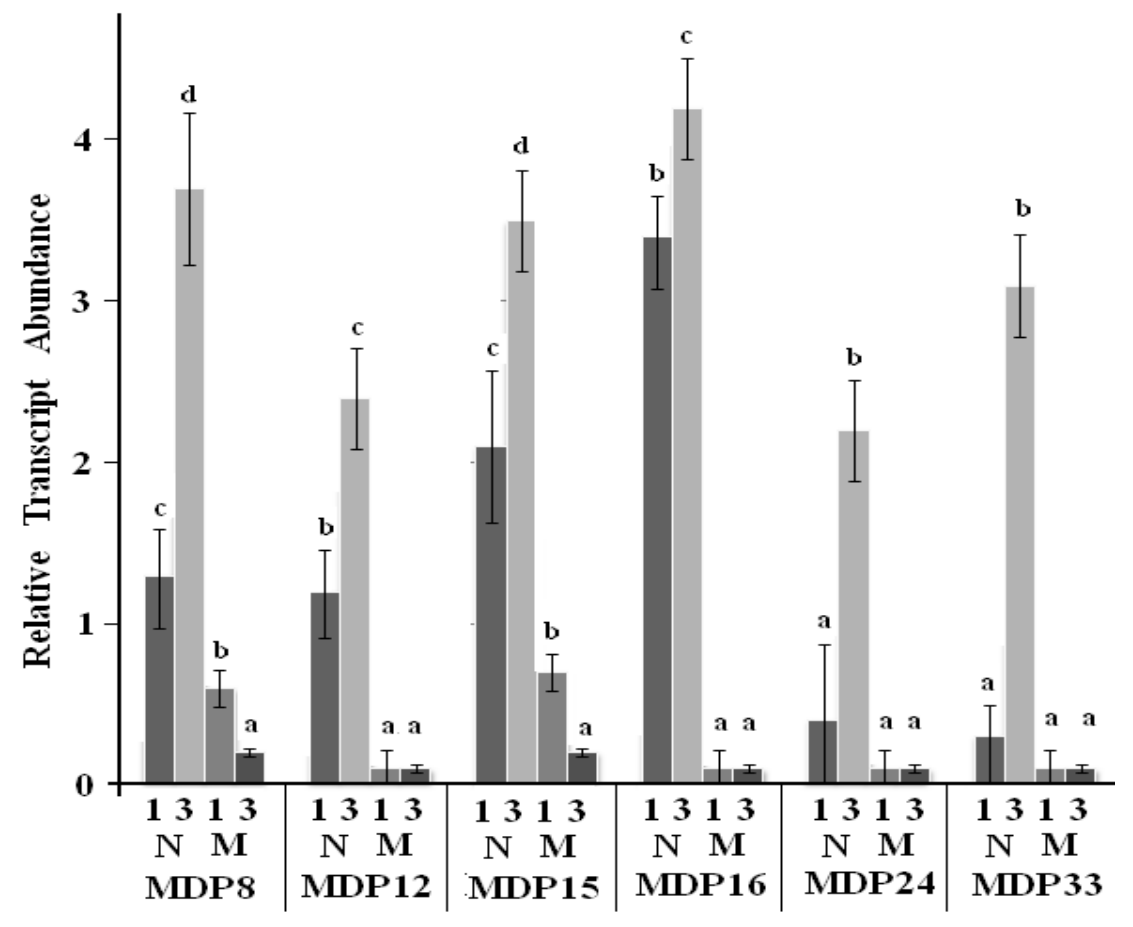


Table 1. Characteristics of putative chymotrypsins, trypsins, and cysteine proteases.

\begin{tabular}{|c|c|c|c|c|c|c|c|}
\hline Gene & MW & pI & $\begin{array}{l}\text { Length } \\
\text { (aa) }\end{array}$ & $\begin{array}{c}\text { First hit } \\
\text { (Accession) }\end{array}$ & Scores & E-value & Organism name \\
\hline \multicolumn{8}{|c|}{ Trypsins } \\
\hline MDP3 & 27657 & 8.6 & 251 & ABM26904 & 264 & $6 E-85$ & Lutzomyia longipalpis \\
\hline MDP5 & 27070 & 5.91 & 246 & XP_001652944 & 249 & $2 \mathrm{E}-79$ & Aedes aegypti \\
\hline MDP90 & 27872 & 8.92 & 251 & ABM26904 & 246 & $4 \mathrm{E}-78$ & L. longipalpis \\
\hline MDP9 & 26803 & 6.98 & 245 & CAA80515 & 277 & $7 E-9 \odot$ & A. gambiae \\
\hline MDP4 & 29676 & 6.38 & 273 & CAA79327 & 282 & $2 \mathrm{E}-91$ & A. gambiae \\
\hline MDP10 & 26751 & 8.12 & 244 & AAB66878 & 207 & $7 E-63$ & An. stephensi \\
\hline MDP12 & 31284 & 8.75 & 283 & АСТ21118 & 183 & $9 E-53$ & Drosophila mojavensis \\
\hline MDP13 & 27666 & 8.78 & 253 & АСТ21122 & 195 & $5 E-58$ & D. mojavensis \\
\hline MDP25 & Truncate & $?$ & $?$ & NP_@001166078 & 370 & $3 E-124$ & Nasonia vitripennis \\
\hline MDP26 & 25870 & 8.05 & 233 & XP_@01658407 & 305 & $9 E-101$ & Ae. aegypti \\
\hline MDP27 & 36858 & 8.4 & 331 & XP_@๑1658409 & 441 & $2 E-153$ & Ae. aegypti \\
\hline MDP28 & 35521 & 8.51 & 321 & AEW46850 & 390 & $3 E-132$ & Chilo suppressalis \\
\hline MDP29 & Truncate & $?$ & $?$ & XP_@01650120 & 461 & $3 E-155$ & Ae. aegypti \\
\hline MDP34 & 105255 & 9.03 & 959 & EFN77168 & 522 & $2 E-168$ & Harpegnathos saltator \\
\hline MDP35 & Truncate & $?$ & $?$ & XP_@๑1870897 & 607 & $\odot \mathrm{E}+\odot \odot$ & Culex quinquefasciatus \\
\hline MDP59 & 38446 & 6.71 & 348 & ADD18853 & 343 & $1 E-112$ & Glossina morsitans \\
\hline MDP61 & 43822 & 8.42 & 393 & NP_649734 & 296 & $2 E-93$ & D. melanogaster \\
\hline MDP71 & 54246 & 8.29 & 491 & XP_001654732 & 418 & $4 E-138$ & Ae. aegypti \\
\hline MDP72 & 73460 & 7.49 & 657 & XP_@001662898 & 586 & $\odot \mathrm{E}+\odot \odot$ & Ae. aegypti \\
\hline MDP74 & Truncate & $?$ & $?$ & NP_729453 & 652 & $\odot \mathrm{E}+\odot \odot$ & D. melanogaster \\
\hline MDP77 & 32416 & 8.72 & 296 & EFN86055 & 167 & $7 E-46$ & Ha. saltator \\
\hline MDP78 & 42673 & 5.64 & 384 & ААТ०9848 & 138 & $7 E-34$ & Anthonomus grandis \\
\hline MDP79 & 28179 & 6.92 & 257 & ACH56915 & 110 & $7 E-26$ & Simulium vittatum \\
\hline MDP23 & 26008 & 7.14 & 235 & CAA80516 & 169 & $7 E-48$ & An. gambiae \\
\hline MDP24 & 21824 & 9.3 & 203 & AAV84270 & 137 & $1 E-36$ & Culicoides sonorensis \\
\hline MDP30 & 71237 & 8.73 & 647 & XP_001651579 & 451 & $1 E-152$ & Ae. aegypti \\
\hline MDP33 & 62722 & 4.99 & 562 & XP_001857202 & 390 & $1 E-129$ & c. quinquefasciatus \\
\hline MDP51 & 64951 & 5.69 & 592 & EHJ76340 & 221 & $3 E-63$ & Danaus plexippus \\
\hline MDP58 & 47573 & 6.59 & 423 & AAD21841 & 284 & $1 E-88$ & Ctenocephalides felis \\
\hline MDP48 & 44640 & 5.72 & 400 & XP_@01655815 & 232 & $8 E-69$ & Ae. aegypti \\
\hline MDP57 & 40874 & 6.23 & 366 & XP_001655816 & 291 & $5 E-92$ & Ae. aegypti \\
\hline \multicolumn{8}{|c|}{ Chymotrypsins } \\
\hline MDP1 & 27569 & 5.58 & 256 & ADR80135 & 256 & $2 \mathrm{E}-81$ & Sitodiplosis mosellana \\
\hline MDP18 & 27138 & 6.17 & 251 & EHJ72680 & 196 & $2 E-58$ & Danaus plexippus \\
\hline MDP19 & 27280 & 5.67 & 246 & ADR80135 & 215 & $1 E-65$ & S. mosellana \\
\hline MDP20 & 29230 & 9.04 & 264 & AAD17493 & 256 & $1 E-81$ & Anopheles darlingi \\
\hline MDP6 & 29239 & 5.47 & 267 & AAA97479 & 204 & $4 \mathrm{E}-61$ & A. stephensi \\
\hline MDP8 & 31322 & 4.98 & 280 & ADR80134 & 188 & $2 E-94$ & S. mosellana \\
\hline
\end{tabular}

